\title{
Peran Model Pembelajaran Scramble dalam Meningkatkan Hasil Belajar IPA
}

\author{
I G. Diyana Putra1 ${ }^{*}$, I W. Widiana², I M. Citra Wibawa ${ }^{3}$ \\ 123 Jurusan Pendidikan Dasar, Universitas Pendidikan Ganesha
}

\begin{abstract}
Abstrak
Tujuan penelitian ini untuk menganalisis besar pengaruh penggunaan mo.del p.embelajaran Scramble terhadap pembelajaran IPA di sekolah dasar. Metode yang digunakan adalah meta-analisis. Sampel penelitian dipilih berdasarkan penjaringan

\section{Kata Kunci:}

Efektivitas, Scramble, IPA Sekolah Dasar dengan ketentuan yang telah ditentukan sebelumnya. Pendekatan dyang d.igunakan adalah deskr.iptif ku.antitatif, yaitu menghitung e.ffectddsize d.ari sepuluh artikel dengan mengiden.tifikasi m.ean, sta.ndar de.viasi dan v.arians dari perhitungand pada uji-t. Dari hasil penelitian diketahui bahwa dari tiga puluh tiga jurnal tersebut hanya ddidapatkan Sepuluh jurnal yang memenuhi kriteria penelitian. Hasil analisis menunjukkan bahwa d7 djurnal memiliki nilai effect size ddalam kategori besar dan 3 jurnal menunjukkan Effect Size dalam dkategori sedang. Rata-rata nilai deffect size model pembelajaran Scra-mble sebesar 1,58. Angka tersebut dbermakna bahwa perlakuan model pembelajaran S-cramble dalam pembelajaran IPA di sekolah dasar dmemberikan pengaruh yang besar terhadap siswa. Implikasi penelitian ini yaitu model ini dapat digunakan sebagai alternative bagi gu.ru sebagai tenaga pendidik dalam membelajarkan IPA agar hasil belajar IPA siswa di sekolah dasar. memenuhi capaian pembelajaran.
\end{abstract}

\begin{abstract}
The purpose of this study was to analyze the effect of using the Scramble learning model on science learning in elementary schools. The method used is metaanalysis. The research sample was chosen based on the selection with predetermined provisions. The approach used is descriptive quantitative, which is to calculate the effect of the ten articles by identifying the mean, standard deviation and variance of the calculations on the t-test. From the results of the study note that of the thirtythree journals, only ten journals were found that met the research criteria. The results of the analysis show that $\mathrm{d} 7$ journals have the effect size value in the large category and 3 journals show the effect size in the medium category. The average value of the size of the Scramble learning model size is 1.58. This figure means that the treatment of the Scramble learning model in learning science in elementary schools has a great influence on students. The implication of this research is that this model can be used as an alternative for teachers as educators in learning science so that the learning outcomes of science students in primary schools meet learning outcomes.
\end{abstract}

* Corresponding author.

E-mail Addresses: - gede.dyana.putra@gmail.com (I G. Diyana Putra) 


\section{PENDAHULUAN}

Daya saingP sumber daya manusia di PIndonesia masihP kalahP jika dibandingkan denganP negara lain. PBerdasarkan PEducation Index yang dikeluarkan oleh Human Devel.opment Re.ports p.ada 2017, I.ndonesia .ad.a d.i po.sisi ketuju.h di. ASEAN dengan skor 0,6.22. Skor terting.gi diraih Singapu.ra, yaitu sebesar 0,832 (Gerintya Scholastica, 2019). HasilP temuanPPPISA (PProgramme foPInternational Student Assesment) P tahun 2015 menunjukkan bahwaP IndonesiaP menempat.i p.eringkat 62 dari 72 negara. y.ang .mengikuti surve.i .dengan c.apaian nilai rata-rat.a k.emampuan sain.s s.iswa I.ndonesia mencap.ai nilai 403. Tahun 2019 peringkat Indonesia justru merosot, skor sains siswaP ada di Pperingkat 70Pdari P78 Pnegara (Tommy, 2019). Kendati pembelajaran IPA di kelas telah dibelajarkan dengan berbagai inovasi.

Ilmu Pengetahua.n-- A.lam-- (IPA) adalah sala.h satu muatan -pembelajaran -di -sekolah -dasar. -IPA siswa dibekali pengetahua.n, -ga.gasan dan -kons.ep -te.ntang alam- sekitar, - yang diperoleh dari pengalama.n m.elalui s.erangkaian pr.oses--i.lmiah -antara -lain penyelidika.n, -p.enyusunan dan penyajian -gagasan--gagas.an(Lestari, 2019). Definisi dan standar kompetensi IPA dalam Permendikbud No. 37 Tahun 2018 mampu menopang amanat UU terkait fungsi dan tujuan pendidikan -nasional yaitu mencerdaskan kehidupan -bangsa untuk --meningkatkan sumber--daya manusia- yang berkualitas-.

Pembelajaran IPA mempunyai peran penting dalam peningkatan -kualitas sumber daya manusia-di Indonesia. Sebagai-- bagian-- dari-- masyarakat-- dunia----, kita --tidak dapat- lepas- dari --pengaruh -perkembangan dan---produk sains- berupa- teknologi-- yang kian mutakhir. Hari ini telah ditemukan artificial intelegent, rekayasa genetika, rekayasa cuaca, dan lain-lain. Semua itu merupakan produk IPA yang membuat setiap orang membutuhkan pengetahuan dan cara berpikir ilmiah tentang Ilmu Pengetahuan Alam(Annuuru et al., 2017). Maka, ilmu pengetahuan alam yang begitu sarat akan kegiatan berpikir dapat menjadi wahana untuk meningkatkan kualitas sumber daya manusia Indonesia, terutama membangun keterampilan berpikirnya. Keterampilan berpikir pada siswa berpengaruh terhadap perkembangan kepribadian siswa (Zubaidah, 2017). Pendidikan ilmu pengetahuan alam juga dapat membantu seseorang untuk mengembangkan--pemahaman dan-kebiasaan berpikir, -sehingga siswa memiliki -sejumlah keterampilan bagi kehidupannya. Keterampilan yang dimaksud adalah keterampilan untuk mengamati, memprediksi dan sikap ilmiah. Ilmu Pengetahuan memiliki sejarah panjang atas kontribusi dalam menciptakan pengetahuan baru dan dimanfaatkan bagi kehidupan manusia dalam skala luas termasuk mendorong perkembangan teknologi (Yuniati, 2018).

Pembelajaran ilmu pengetahuan alam juga dapat dijadikan pendekatan untuk membangun karakter pada siswa. Melalui ilmu pengetahuan alam siswa dapat mengenal dirinya dan tuhannya(Mulyani et al., 2018). Model pendidikan karakter yang dipadukan- dengan- pembelajaran- bidang- studi- dan dilandasi pengembangan- kultur- sekolah-, dapat -meningkatkan -hasil studi dan karakter siswa.Pendidikan karakter yang diimplementasikan pada berbagai disiplin ilmu dapat menciptakan sebuah pengalaman yang bermakna bagi siswa karena dalam pembelajaran tersebut siswa diajak untuk memahami, menginternalisasi, dan mengaktualisasikan proses pembelajaran. Pembelajaran ilmu pengetahuan alam dan berbagai mata pelajaran lain, dapat memberikan peran dalam penguatan karakter siswa, missal siswa dikenalkan mengenai peran kerjasama dalam tim, kejujuran, komitmen, kejujuran, dan lain-lain(Wicaksono, 2016). Pendidikan karakter bisa dipahami secara komprehensif. Pemahaman tersebut juga yang akan menumbuhkan kecintaan dan apresiasi pada suatu hal. Maka, pembelajaran ilmu pengetahuan alam pun dapat menjadi wahana pendidikan karakter secara terintegrasi (Zubaidah, 2017). Pendekatan ini pun berarti bahwa sejak sekolah dasar, ilmu pengetahuan penting bagi siswa sebagai salah satu upaya untuk mencapai kualitas pendidikan yang diamanatkan.

Untuk mencapai kualitas pendidikan yang diamanatkan, .Pemerintah Ptelah Pberusaha Pmeningkatkan PmutuPpendidikan melalui Pwajib Pbelajar --12 Ptahun, adanya pendidikanPkarakter, Ppembaharuan kurikulum, Pmeningkatkan Panggaran Ppendidikan melalui alokasi APBN, Ppeningkatan Pkompetensi Pguru Pmelalui Psertifikasi, Ppengadaan dan perbaikan saranaP dan Pprasarana sekolah Pmelalui Pdana Pbantuan PoperasionalPsekolah (BOS). PDalam Pproses Pkegiatan Pbelajar mengajarP diperlukanP metodeP, Ppendekatan, Pteknik atau model pembelajaran Pyang tepat. HalP tersebutP dimaksudkanPagar tujuan Ppembelajaran yang diharapkan Pdapat tercapaiP denganP baik. Metode Ppembelajaran Pmerupakan Pmedia transformasiP dalamP pembelajaran, agar kompetensi Pyang diharapkan Pdalam Ppembelajaran tercapaiP(Maesaroh, 2018).

Namun, Kesenjangan yang nampak pada ulasan ini adalah berbagai upaya dalam meningkatkan kualitas siswa yang belum optimal. Hal tersebut dipertegas dengan prestasi siswa di dunia internasional berdasarkan perolehan beberapa hasil survey yang telah disebutkan menurun. Padahal, berdasarkan hasil penelusuran di garba rujukan digital, ada ribuan hasil riset maupun penelitian tindakan kelas yang telah dilakukan mengenai inovasi pembelajaran ilmu pengetahuan alam di kelas. Namun, belum ada penelitian 
tindak lanjut mengenai model penelitian yang memberikan pengaruh besar terhadap pembelajaran IPA. Sebagai bangsa yang besar sudah seharusnya Indonesia meningkatkan budaya literasi sains sebagai penunjang kecakapan hidup abad21 (Yuliati, 2017). Maka dari itu, perlu dilakukan penelitian lanjut untuk mencari tahu dan menganalisis suatu model pembelajaran yang memberikan pengaruh besar bagi pembelajaran IPA. Urgensi penelitian lanjut juga diungkapkan pada (Dewi, 2016) penelitian mengenai model inkuiri terhadap sikap ilmiah dalam pembelajaran sains. Hal ini menekankan peran penting penelitian lanjut terhadap suatu pengembangan ilmu pengetahuan (Chusna, 2017) . Hasil penelitian ini dapat menjadi bahan pertimbangan guru di kelas dalam berinovasi dan memberikan pembelajaran yang bermakna pada ilmu pengetahuan alam di sekolah dasar.

Dalam proses kegiatan belajar mengajar diperlukan metode, .pendekatan, teknik atau model pembelajaran yang tepat. Hal tersebut dimaksudkan agar tujuan pembelajaran yang diharapkan dapat .tercapai dengan baik. .Metode pembelajaran merupakan media transformasi dalam pembelajaran, agar kompetensi yang diharapkan dalam pembelajaran .tercapai (Maesaroh, 2018). .Metode yang bervariasi sesuai dengan kompetensi yang diharapkan akan merangsang minat dan motivasi peserta didik, dengan motivasi yang kuat, maka prestasi belajar akan meningkat(Bagja \& Yuliana, 2019). Apabila antara pendekatan, strategi, metode, dan model pembelajaran sudah .terangkai menjadi satu kesatuan yang utuh maka .terbentuklah apa yang disebut dengan model pembelajaran. Sehingga model pembelajaran menjadi suatu kesatuan utuh salah satu faktor eksternal penentu hasil belajar. Peningkakan kualitas dan efektivitas pembelajaran IPA telah .dilakukan melalui berbagai upaya. Salah satu dari upaya tersebut adalah .penggunaan .model pembelajaran Scramble. Model scramble relevan .digunakan untuk meningkatkan hasil belajar siswa karena model ini .mampu .merangsang siswa untuk berpikir kritis, kreatif, aktif, efektif, interaktif dan .menyenangkan bagi siswa(Rismawati, 2019).

Pengamatan pendahuluan dilakukan pada penelitian ini dengan mengamati berkas data penelitian yang paling banyak dilakukan dan dipublikasikan dalam berbagai jurnal nasional yang terakreditasi. Hasilnya, peneliti menemukan 45 judul penelitian model pembelajaran Scramble dalam materi IPA yang dipublikasikan dalam rentang tahun 2013-2019. Data dari berbagai penelitian terdahulu dalam bidang pendidikan tersedia cukup melimpah dalam bentuk jurnal-jurnal terpublikasi dan juga skripsi-skripsi mahasiswa dari berbagai kampus yang tersebar di Indonesia. Namun, tidak banyak penelitian dan kajian terhadap hasil-hasil penelitian untuk merangkum dan menguji kembali keefektifan hasil suatu tema penelitian. Khususnyaa penelitian meta-analisis terbaru mengenai model pembelajaran Scramble dalam pembelajaran IPA di jenjang pendidikan dasar. Berangkat dari masalah dan latar belakang tersebut, akhirnya penelitian inimelakukan penelitian meta-analisis jurnal nasional untuk melihat besar pengaruh penggunaan model pembelajaran scramble untuk diterapkan secara keseluruhan, dengan judul penelitian "Meta-Analisis Penggunaan Model Scramble dalam Pembelajaran IPA di Sekolah Dasar".

Meta-analisis Pdalam dunia pendidikan mulai dilakukan sekitar tahun 1970-an oleh PGene Glass, PFrank L. SchmidtP dan John E. Hunter. Gene Glass pada tahun 1976 mendeklarasikanP pentingnya Pmelakukan penelitian meta-analisis dalam bidang pendidikan berdasarkan melimpahnya hasil studi bidang pendidikan yang tidak ditindaklanjuti. Meta-analisis merupakan Pmetode telaah sistematik yang disertai teknik statistik untuk menghitung Pkesimpulan beberapa hasil penelitian(Assyifa, 2017). Glass mendefinisikan meta-analisis sebagai analisis statistik dari kumpulan banyak hasil penelitian individu sebagai pengintegrasian hasil temuan(Anugraheni, 2018).

Penelitian ini relevan untuk dilakukan karena ada penelitian sebelumnya yang-- -mendukung seperti penelitian tahun 2019 oleh Putri Utami. Judul penelitiannya adalah-- -efektivitas penggunaan model kooperatif dalam pembelajaran Biologi. Penelitian ini pun-- -menggunakan metode meta-analisis dengan hasilnya menunjukkan bahwa pembelajaran-- -kooperatif memberikan pengaruh yang lebih efektif dan patut diterapkan dalam- -pembelajaran Biologi. Hasil penelitiannya menunjukkan model kooperatif secara- -keseluruhan mampu meningkatkan hasil belajar Biologi siswa pada kelompok eksperimen- -dari kelompok kontrol, dengan effect size 0,36- yang berarti dalam kategori besar. Penelitian- -kedua oleh (Sutini, 2014) dengan judul studi meta analisis laporan pemantapan -kemampuan-profesional- (PKP-) -mahasiswa program S-1 PGSD- di U-PBJJ-UT- -Surabaya. -Penelitian ini- -bertujuan untuk memberikan informasi yang jelas dan komprehensif mengenai hasil-hasil- -laporan -PKP sehingga dapat dipergunakan untuk memperbaiki model pembelajaran di SD. -Hasilnya- menunjukkan secara umum berbagai strategi yang dipilih telah dibuktikan dalam- -praktek -perbaikan pembelajaran- -ternyata memiliki kontribusi yang cukup besar dalam- -memperbaiki- model pembelajaran- di SD karena bukan saja model-model pembelajaran- -yang -beragam tetapi beberapa -diantaranya memiliki inovasi yang patut dijadikan sebagai- -model pembelajaran di SD-. -Penelitian initurut merekomendasikan agar dilakukan meta- -analisis terhadap berbagai -hasil penelitian- dari jenis penelitian lain. Terakhir, dari Rahma- (Diani et al., 2016) dengan judul uji effect size model pembelajaran scrambleP dengan media- video terhadap hasil belajar fisika peserta didik kelas X Man 1 Pesisir Barat. Hasil- -penelitiannya 
menunjukkan hasil uji effect size sebesar -0,8. Hasil ini menunjukkankan-- -bahwa model pembelajaran ScramblePdengan media video dapat mempengaruhi hasil- -belajar fisika peserta didik sebanyak $79 \%$. Berdasarkan hasil penelitian yang relevan dari -semua paparan hasil penelitian tersebut dapat memberikan gambaran bahwa -pembelajaran- -dengan menggunakan model PScramble memberi pengaruh yang besar -terhadap- -pembelajaran IPA di sekolah dasar. Berdasarkan ketiga penelitian terdahulu tidak -ditemukan- -penelitan lanjut di sekolah dasar terutama mengenai model pembelajaran Pscramble. Inilah- -yang menjadi poin pembaharuan penelitian yang akan dilakukan-.

Penelitian -meta-analisis perlu dilakukan untuk menguji- -keefektifan -hasil-hasil -penelitian sebelumnya(Benyamin et al., 2020). Hasil-hasil penelitian yang- dianalisis -kemudian -diinterpretasikan. Penerapan model pembelajaran PScramble- memberi -kesempatan kepada siswa untuk meningkatkan keterampilan -kognitif -dan afektifnya. Siswa -yang diajari dengan model ScrambleP akan memperoleh hasil pembelajaran IPA yang lebih -tinggi -di sekolah dasar.

Sebagai penjelasan atas kerangka berpikir penelitian ini, masalah yang diangkat-- adalah seperti yang telah diuraikan sebelumnya.Banyak penelitian mengenai inovasi-- pembelajaran IPA di sekolah namun justru literasi sains merosot pada survey PISA. Setelah-- ditelusuri ada banyak inovasi pembelajaran IPA menggunakan model Scramble. Padahal, -- model ini juga efektif pada pembelajaran bahasa (Yunita Puspitasari, 2019). Penelusuran selanjutnya tidak ditemukan penelitian lanjutatau metaanalisis mengenai model scramble-- terhadap Ilmu Pengetahuan Alam. Itulah poin yang dijadikan dasar urgensi penelitian lanjut-- atau meta-analisis ini. Meta-analisis ini disusun dengan mengumpulkan besaran pengaruh-- (Effect Size) dari sample yang telah dikumpulkan. Setiap sample dianalisis satu per satu-- proporsi untuk mengetahui besaran pengaruhnya, apabila disebutkan komponen penting-- yang diperlukan seperti varian, jumlah sample, mean, standar deviasi, dll. Setelah terkumpul-- nilai besaran efeknya kemudian dicari reratanya. Reratanya ini kemudian di intepretasikan-- dalam tabel besaran oleh cohen. Untuk lebih memudahkan penjelasan tersebut.

\section{METODE PENELITIAN}

Jenis Penelitian ini menggunakan jenis deskriptif kuantitatif. Sedangkan metode penelitian yang digunakan yaitu meta-analisis. Meta-analisis merupakan literature review atau dengan mereview kepustakaan, menganalisis hasil penelitian yang ada di situs-situs resmi atau yang telah dipublikasikan secara resmi melalui media publikasi internal kampus dan/atau media publikasi ilmiah. Pentingnya metaanalisis banyak diungkapkan oleh banyak ahli, salah satunya (Hernandez et al., 2020) menyatakan bahwa meta-analisis menyediakan solusi atas masalah yang diamati dalam penemuan-penemuan beragam studi serupa. Formulasi dari meta-analisis yang digunakan yaitu mencari rata-rata dari semua hasil uji effect size yang terkumpul ini juga merupakan instrument dari analisis data.Variabel terikat dari penelitian ini adalah pembelajaran IPA di sekolah dasar dan variabel bebasnya adalah model pembelajaran PScramble. Populasi penelitian ini adalah jurnal yang terhimpun dalam Garuda :Garba Rujukan Digital. Jurnal-jurnal yang dikumpulkan berkaitan dengan model pembelajaran ScramblePdalam pembelajaran IPA. Sampel dalam penelitian berupa artikel yang telah dipublikasikan secara nasional, khususnya artikel yang telah dipublikasikan dengan kriteria (1) dibuat atau ditulis oleh peneliti atau mahasiswa, (2) penelitian dilakukan di Indonesia, (3) penelitian dalam rentang 2010 sampai 2020, (4) penelitian dilakukan pada jenjang pendidikan SD, (5) subyek penelitian berupa penggunaan model Scramble terhadap pembelajaran IPA, (6) Isi artikel memenuhi data yang dibutuhkan dalam menghitung effect size. Setelah dianalisis kemudian diintepretasikan menggunakan klasifikasi oleh cohen (Handayani et al., 2018)seperti berikut ;

Tabel 1. Intepretasi effect size

\begin{tabular}{ccc}
\hline Besar d & Intepretasi \\
\hline $\mathrm{d} \geq 0,8$ & Besar \\
$0,5 \leq \mathrm{d}<0,8$ & Sedang \\
$\mathrm{d}<0,5$ & Rendah \\
\hline
\end{tabular}

Penelitian meta-analisis disebut juga penelitian meta atau meta research. Penelitian ini menggunakan pustaka, buku ataupun jurnal sebagai sumber datanya(Sari, 2020). Penelitian ini akan mengambil beberapa penelitian yang memiliki satu topik atau tema yang sama dalam penelitian ini. Metode ini digunakan untuk meringkas, merangkum dan memperoleh intisari hasil temuan dari sejumlah penelitian. Meta-analisis dapat bersifat kuantitatif dan merupakan suatu analisis statistik untuk memperoleh serangkaian informasi yang berasal dari sejumlah data dari penelitian-penelitian 
sebelumnya(Hutagalung \& Utomo, 2017). Dilihat dari prosesnya, meta-analisis merupakan suatu studi observasional retrospektif, dalam arti peneliti membuat rekapitulasi fakta tanpa melakukan manipulasi eksperimental. Proses perencanaan penelitian meta-analisis dimulai dengan 1) perumusan masalah, 2) pengumpulan dan penilaian data, 3) analisis dan penafsiran data dan, 4) laporan penelitian. Perumusan masalah adalah langkah awal dari setiap jenis penelitian. Secara garis besar, dalam perumusan masalah peneliti harus menentukan penelitian yang akan digunakan. Penelitian yang akan digunakan harus memiliki prosedur perlakukan, kontrol dan percobaan serta memiliki ukuran hasil penelitian yang sama. Selanjutnya adalah pengumpulan data. Data meta-analisis yang dikumpulkan terdiri dari kumpulan isi penelitian dari karakteristik penelitian dan besarnya efek. Selanjutnya data dikumpulkan dan disusun dalam bentuk lembar pengkodean. Lembar pengkodean disusun untuk memberikan informasi mengenai penelitian terkait, serta memudahkan peneliti untuk menganalisis penelitiaanya(Utami, 2019).

\section{ANALISIS DAN PEMBAHASAN}

Berdasarkan penelusuran berbagai sumber jurnal, ditemukan 33 artikel yang berkaitan dengan variabel. Tahun penelitian pada 33 jurnal berada pada rentang waktu 2013 hingga 2019. Co-variabel bebas dalam populasi ditemukan beragam. Keberagaman ini akan menunjukkan bahwa model scramble mampu dimodifikasi dengan berbagai media pembelajaran untuk mencapai tujuan pembelajaran. Terdapat 7 ragam co-variabel dengan dominasi variabel bebas tanpa co-variabel. Variabel terikat dalam populasi yang didapat juga beragam, ada 8 ragam dengan dominasi variabel terikat adalah hasil belajar IPA. 22 dari 33 sampel dalam populasi menunjukkan variabel terikat merupakan hasil belajar IPA. 33 jurnal tersebut selanjutnya dilakukan analisis lanjutan untuk dihitung effect size dari masing-masing jurnal sehingga mengkrucut menjadi sepuluh jurnal yang sesuai dengan kriteria yang sudah ditentukan. Hasilnya sebagai berikut dalam Tabel ;

Tabel 2. Data hasil analisis keseluruhan sample

\begin{tabular}{cccccc}
\hline No & $\begin{array}{c}\text { Kode } \\
\text { Jurnal }\end{array}$ & Wilayah & Variabel terikat & Nilai Effect Size & Keterangan \\
\hline 1 & A8 & Bali & Hasil Belajar IPA & 2,8 & Efek Besar \\
2 & A4 & Jawa Tengah & Hasil Belajar IPA & 2,69 & Efek Besar \\
3 & A3 & Bali & Hasil Belajar IPA & 2,5 & Efek Besar \\
4 & A1 & Bali & Hasil Belajar IPA & 2,14 & Efek Besar \\
5 & A2 & Bali & Hasil Belajar IPA & 1,74 & Efek Besar \\
6 & A10 & Bali & Kompetensi Pengetahuan IPA & 1,13 & Efek Besar \\
7 & A6 & Bali & Hasil Belajar IPA & 0,86 & Efek Besar \\
8 & A9 & Bali & Hasil Belajar IPA & 0,7 & Efek Sedang \\
9 & A7 & Jawa Timur & Hasil Belajar IPA & 0,7 & Efek Sedang \\
10 & A5 & Bali & Hasil Belajar IPA & 0,6 & Efek Sedang \\
\hline \multicolumn{7}{r}{} \\
\hline
\end{tabular}

Hasil analisis menunjukkan bahwa 7 dari 10 jurnal memiliki efek besar dan 3 dari 10 menunjukkan efek sedang. Secara keseluruhan rata-rata effect size pembelajaran model Scramble yang dikaitkan dengan penelitian-penelitian yang bersifat eksperimental dari sepuluh artikel yang dianalisis mencapai angka 1,58 dan masuk dalam kategori efek yang besar. Rata-rata tersebut menguatkan bahwa pembelajaran model Scramble secara keseluruhan memiliki pengaruh yang besar dalam pembelajaran IPA di sekolah dasar. Ini merupakan jawaban atas penelitian yang dilakukan.

Hasil ini saling menguatkan atas penelitian sebelumnya oleh Rahma Diani (2016) menunjukkan kan bahwa model pembelajaran Scramble dengan media video dapat mempengaruhi peningkatan hasil belajar fisika peserta didik. Berdasarkan hasil penelitian yang relevan dari semua paparan hasil penelitian tersebut dapat memberikan gambaranbahwa pembelajaran dengan menggunakan model Scramble memberi pengaruh yang besar terhadap pembelajaran IPA di sekolah dasar.Hasil analisis yang menunjukkan pengaruh besar dapat didukung oleh penjelasan bahwa model pembelajaran scramble memiliki kelebihan membuat siswa lebih teliti dan cermat dalam melihat jawaban dan membuat siswa mampu untuk berpikir kritis. Hal ini pula dapat tercapai karena dalam proses pembelajaran siswa memungkinkan untuk belajar sambil bermain. Hasil ini pun sejalan dengan hasil penelitian sebelumnya yang menyebutkan model pembelajaran memiliki inovasi yang patut dijadikan sebagai model pembelajaran di sekolah dasar. Khususnya model pembelajaran Scramble terhadap pembelajaran IPA. 
Kontribusi media pembelajaran sebagai co-variabel bebas mendukung model pembelajaran Scramble memberikan pengaruh yang besar bagi peningkatan hasil belajar dalam pembelajaran IPA. Novelty dari penelitian ini adalah jenis dari penelitiannya terhadap variabel terikat yaitu Ilmu Pengetahuan Alam. Tidak ditemukan penelitian lanjut atau meta-analisis mengenai media scramble terhadap Ilmu pengetahuan Alam di sekolah dasar. Pada berbagai rujukan, meta-analisis model ini justru terhadap pembelajaran bahasa (Sugiharti \& Riftina, 2019).

Penelitian yang diambil dan dianalisis merupakan penelitian kuasi eksperimental, sehingga penelitian initidak dapat mengontrol kemungkinan adanya variabel luar yang terlibat dan mempengaruhi penelitian dalam sampel penelitian yang diambil. Hal tersebut sesuai dengan pernyataan (Arif \& Rijanto, 2017)yang menyebutkan bahwa meta-analisis yang dilakukan terhadap studi observasional, akan mengundang lebih banyak masalah baik dalam metodologi maupun perangkat statistika yang digunakan, karena bias lebih mengancam pada studi observasional dibanding pada uji klinis. Oleh karena itu, penelitian ini harus teliti dan hati-hati dalam melaporkan hasil penelitian. Penelitian pendahuluan dilakukan untuk menemukan artikel-artikel yang memiliki tema penelitian penggunaan model pembelajaran scramble. Dalam penelitian berhasil menemukan lebih dari tiga puluh tiga artikel jurnal, namun hanya bisa menganalisis sepuluh artikel yang memenuhi kriteria. Jurnal-jurnal yang tidak memenuhi kriteria, sebagian besar bukan karena reputasi atau akreditasi jurnalnya, tetapi sebagian besar tereliminasi dari proses analisis karena dalam isinya tidak ada angka atau hasil statistik yang dibutuhkan untuk menghitung effect size. Komponen statistika penelitian berupa jumlah sampel, standart deviasi atau nilai rerata menjadi hal dasar yang harus ada dan ditampilkan dalam setiap jurnal penelitian eksperimen, tetapi di lapangan banyak ditemukan jurnal-jurnal yang tidak mencantumkan bagian statistika tersebut. Bahkan penelitian inimenemukan ada beberapa jurnal yang tabel perhitungan statistikanya tidak ditampilkan sebagaimana mestinya. Tabel yang seharusnya menjadi salah satu informasi penting dalam laporan penelitian tersebut, dihilangkan beberapa bagian pentingnya.

Implikasi penelitian ini diketahui berdasarkan hasil analisis uji Effect Size dan merupakan konsekuensi logis dari simpulan penelitian. Hasil penelitian menunjukkan rerata dari 10 artikel mengenai model pembelajaran Scramble dengan pembelajaran IPA di sekolah dasar adalah 1,58. Nilai tersebut berada pada klasifikasi pengaruh besar. Maka, dapat ditarik informasi bahwa model pembelajaran Scramble memberikan pengaruh besar terhadap pembelajaran IPA di sekolah dasar. Hasil penelitian ini dapat digunakan sebagai alternative bagi guru sebagai tenaga pendidik dalam membelajarkan IPA agar hasil belajar IPA siswa memenuhi capaian pembelajaran. Melalui model pembelajaran Scramble, siswa diajak untuk berpikir teliti dan efektif. Melalui model ini juga siswa akan belajar dengan suka cita karena model ini mengajak siswa untuk bermain(Anggraini, 2018). Siswa akan dikondisikan dalam suasana yang tidak tegang ataupun tertekan. Mengajak siswa untuk bermain sambil belajar, juga berarti mengajak siswa untuk belajar dengan penuh makna dan pengalaman(Komariah, 2018). Siswa tidak pasif sehingga pendekatan siswa sebagai pusat pembelejaran akan terpenuhi. Pembelajaran yang bermakna dan mengesankan tidak akan mudah dilupakan oleh siswa. Dalam hasil penelitian ini, banyak ditemukan pembelajaran model scramble ditunjang oleh berbagai media. Peran media ini juga menambah antusias siswa dan meningkatkan perhatian siswa pada pembelajaran (Yaumi, 2018).

\section{KESIMPULAN}

Temuan analisis hasil penelitian yang telah dilakukan memberikan kesimpulan bahwa pembelajaran model Scramble secara keseluruhan mampu meningkatkan hasil belajar IPA siswa pada kelompok eksperimen dari kelompok kontrol, dengan effect size 1,58 yang berarti dalam kategori besar. Hal tersebut menunjukkan bahwa pembelajaran model Scramble memberikan pengaruh yang lebih efektif dan patut diterapkan dalam pembelajaran IPA di sekolah dasar. Model pembelajaran Scramble dapat dijadikan alternatif pembelajaran untuk meningkatkan pembelajaran IPA siswa di sekolah dasar. Ratarata besar pengaruh penggunaan model pembelajaran Scramble terhadap pembelajaran IPA termasuk dalam kategori besar. Walaupun hasilnya demikian, berdasarkan proses dan temuan penelitan metaanalisis yang telah dilakukan menunjukkan adanya beberapa kekurangan. Pengambilan sampel penelitian sebaiknya diambil dari lebih banyak sumber jurnal yang diterbitkan baik secara online maupun offline. Semakin banyak sampel yang digunakan dalam suatu penelitian, maka semakin baik kualitas penelitian tersebut dibandingkan dengan penelitian yang menggunakan sampel yang sedikit. 


\section{DAFTAR PUSTAKA}

Anggraini, P. (2018). Pengaruh Model Pembelajaran Kooperatif Tipe Scramble Terhadap Hasil Belajar Ips Siswa Kelas V Sd Negeri 4 Metro Utara. Digital Repository Unila. Http://Digilib.Unila.Ac.Id/32413/

Annuuru, T. A., Johan, C. R., \& Ali, M. (2017). No Title. Edutechnologia, 1(2), 137. Https://Ejournal.Upi.Edu/Index.Php/Edutechnologia/Issue/View/922

Anugraheni, I. (2018). Meta Analisis Model Pembelajaran Problem Based Learning Dalam Meningkatkan Keterampilan Berpikir Kritis Di Sekolah Dasar. Polygot.

Arif, S., \& Rijanto, T. (2017). Model Pembelajaran Kooperatif Tipe Snowball Throwing Terhadap Hasil Belajar Dan Minat Peserta Didik (Meta-Analisis Data). Jurnal Pendidikan Teknik Elektro.

Assyifa, H. (2017). Perbandingan Efektifitas Silodosin Dan Tamsulosin Sebagai Tatalaksanaan Lower Urinary Tract Symptom (Luts) Pada Pembesaran Prostat Jinak: Telaah Sistematis Dan Meta Analisis. Repositori Institusi Universitas Sumatera Utara. Http://Repositori.Usu.Ac.Id/Handle/123456789/4596

Bagja, S. W., \& Yuliana, D. (2019). Penerapan Model Pembelajaran Discovery Learning Meningkatkan Motivasi Dan Hasil Belajar Pendidikan Kewarganegaraan 1. Jurnal Rontal Keilmuan Pkn.

Benyamin, P. Issak, Mahendra, Y., \& Santosa, D. S. S. (2020). Metode Pembelajaran Untuk Meningkatkan Prestasi Belajar Siswa Pada Mata Pelajaran Pendidikan Agama Kristen: Studi Meta Analisis. Sotiria : Jurnal Teologi Dan Pelayanan Kristiani, 03(01). Http://Sttpaulusmedan.Ac.Id/EJournal/Index.Php/Sotiria/Article/View/17

Chusna, P. A. (2017). Pengaruh Media Gadget Pada Perkembangan Karakter Anak. Dinamika Penelitian: Media Komunikasi Sosial Keagamaan. Https://Doi.Org/10.21274/Dinamika/2017.17.2.315-330

Dewi, P. S. (2016). Perspektif Guru Sebagai Implementasi Pembelajaran Inkuiri Terbuka Dan Inkuiri Terbimbing Terhadap Sikap Ilmiah Dalam Pembelajaran Sains. Tadris: Jurnal Keguruan Dan Ilmu Tarbiyah. Https://Doi.Org/10.24042/Tadris.V1i2.1066

Diani, R., Yuberti, Y., \& Syafitri, S. (2016). Uji Effect Size Model Pembelajaran Scramble Dengan Media Video Terhadap Hasil Belajar Fisika Peserta Didik Kelas X Man 1 Pesisir Barat. Jurnal Ilmiah Pendidikan Fisika Al-Biruni. Https://Doi.Org/10.24042/Jpifalbiruni.V5i2.126

Gerintya Scholastica. (2019). Indeks Pendidikan Indonesia Rendah, Daya Saing Pun Lemah. Tirto.Id.

Handayani, M. W., Swistoro, E., \& Risdianto, E. (2018). Pengaruh Model Pembelajaran Problem Solving Fisika Terhadap Kemampuan Penguasaan Konsep Dan Kemampuan Pemecahan Masalah Siswa Kelas X Mipa Sman 4 Kota Bengkulu. Jurnal Kumparan Fisika. Https://Doi.Org/10.33369/Jkf.1.3.3644

Hernandez, A. V., Marti, K. M., \& Roman, Y. M. (2020). Meta-Analysis. In Chest. Https://Doi.Org/10.1016/J.Chest.2020.03.003

Hutagalung, T., \& Utomo, D. (2017). Meta-Analisis Variasi Penelitian Dari Peneliti Akuntansi Di Indonesia.

Komariah, K. (2018). Peningkatan Kualitas Pembelajaran Serta Aktifitas Belajar Siswa Pada Pelajaran Pkn Melalui Penerapan Model Pembelajaran Kooperatif Tipe Bermain Kocok Dadu Di Smp Negeri 5 Kota Serang. Tarbawi: Jurnal Keilmuan Manajemen Pendidikan. Https://Doi.Org/10.32678/Tarbawi.V4i01.1774

Lestari, T. (2019). Pengembangan Rencana Pelaksanaan Pembelajaran Mata Pelajaran Akuntansi Dasar Berorientasi Peraturan Dirjen Dikdasmen Kemendikbud No. 07/D. D5/Kk/2018. Seminar Nasional Keindonesiaan Iv. Http://Conference.Upgris.Ac.Id/Index.Php/Snk/Article/View/542

Maesaroh, E. (2018). Implementasi Metode Qira'ati Dalam Pembelajaran Membaca Al-Qur'an Di Lembaga 
Pendidikan Qur'an Dewasa (Lpqd) Al Falah Bobosan Kecamatan Purwokerto Utara (Doctoral Dissertation, Iain). Digital Repository: Institut Agama Islam Negeri Purwokerto.

Mulyani, A., Asyhar, R., Yelianti, U., \& Syarial. (2018). Integrasi Ilmu Pengetahuan Alam Dan Nilai-Nilai Islam Untuk Pembangunan Karakter Peserta Didik Di Madrasah Aliyah. Journal Of Education In Mathematics, Science, And Technology.

Rismawati, M. M. (2019). Pengaruh Model Pembelajaran Kooperatif Tipe Scramble Terhadap Minat Dan Hasil Belajar Matematika Siswa Kelas Viii Di Mts Darul Falah Bendiljati Kulon Sumbergempol Tulungagung. [Iain Tulungagung: Institutional Repository]. Http://Repo.IainTulungagung.Ac.Id/Id/Eprint/11730\%0a

Sari, R. K. (2020). Efektivitas Penggunaan Model Pembelajaran Role Playing Terhadap Ketrampilan Berbicara Pada Bahasa Indonesia Tingkat Sd. Universitas Pahlawan, 01(02). Https://Journal.Universitaspahlawan.Ac.Id/Index.Php/Jpdk/Article/View/582/0

Sugiharti, R. E., \& Riftina, Y. (2019). Upaya Meningkatkan Penguasaan Kosakata Bahasa Inggris Melalui Model Scramble Pada Siswa Kelas 4 Sdn Jatimulya 04 Tambun Selatan. Indonesian Journal of Primary Education. Https://Doi.Org/10.17509/Ijpe.V2i2.15096

Sutini. (2014). ) Studi Meta Analisis Laporan Pemantapan Kemampuan Profesional (Pkp) Mahasiswa Program S-1 Pgsd Di Upbjj-Ut Surabaya. Repository.Ut.Ac.Id.

Tommy, K. (2019). Skor Terbaru Pisa: Indonesia Merosot Di Bidang Membaca, Sains, Dan Matematika. Liputan6. Https://Www.Liputan6.Com/Global/Read/4126480/Skor-Terbaru-Pisa-IndonesiaMerosot-Di-Bidang-Membaca-Sains-Dan-Matematika

Utami, P. (2019). Meta-Analisis Penggunaan Model Kooperatif Dalam Pembelajaran Biologi. Http://Repository.Uinjkt.Ac.Id/Dspace/Bitstream/123456789/49223/1/Meta-Analisis 20-0110.Pdf

Wicaksono, A. G. (2016). Penguatan Pendidikan Karakter Melalui Pembelajaran Ilmu Alamiah Dasar. 11(02). Http://Www.Ejurnal.Unisri.Ac.Id/Index.Php/Widyawacana/Article/Download/1483/1307

Yaumi, M. (2018). Media Dan Teknologi Pembelajaran. In Jakarta.

Yuliati, Y. (2017). Literasi Sains Dalam Pembelajaran Ipa. Jurnal Cakrawala Pendas. Https://Doi.Org/10.31949/Jcp.V3i2.592

Yuniati, S. (2018). Implementasi Pendidikan Karakter Dalam Pembelajaran Matematika Melalui Pendekatan Konstektual. Al-Khwarizmi: Jurnal Pendidikan Matematika Dan Ilmu Pengetahuan Alam. Https://Doi.Org/10.24256/Jpmipa.V2i1.101

Yunita Puspitasari, A. (2019). Improving Students In Writing Skill By Using Scrambled Picture In Narrative Text. Jurnal Ilmiah Bahasa Dan Sastra. Https://Doi.Org/10.21067/Jibs.V5i1.3183

Zubaidah, S. (2017). Pembelajaran Sains (Ipa) Sebagai Wahana Pendidikan Karakter. - Universitas Negeri Malang.Https://Www.Researchgate.Net/Profile/Siti_Zubaidah5/Publication/318040732_Pembelaj aran_Sains_Ipa_Sebagai_Wahana_Pendidikan_Karakter/Links/59565147aca272fbb37d2771/Pemb elajaran-Sains-Ipa-Sebagai-Wahana-Pendidikan-Karakter.Pdf. 